\title{
Dietary Habits of the Introduced Cane Toad Bufo marinus (Amphibia: Bufonidae) on Ishigakijima, Southern Ryukyus, Japan ${ }^{1}$
}

\author{
Noriko Kidera, ${ }^{2}$ Nontivich Tandavanitj, ${ }^{3}$ Daehyun Ob, ${ }^{2}$ Nozomi Nakanishi, ${ }^{4}$ Aya Satob,${ }^{4}$ \\ Tetsuo Denda,${ }^{4}$ Masako Izawa,${ }^{4}$ and Hidetoshi Ota ${ }^{5,6}$
}

\begin{abstract}
We examined dietary habits of the introduced cane toad Bufo marinus at three sites representing different types of habitats (pond, forest, and rice paddy) on Ishigakijima Island, southern Ryukyus, Japan. Stomach contents analysis revealed that the toad mostly utilizes terrestrial arthropods, of which hymenopterans (mostly ants), adult coleopterans, hemipterans, and araneans dominated in the frequency of occurrence, hymenopterans in the numerical proportion, and larval lepidopterans, adult coleopterans, and larval dipterans in the volumetric proportion. Comparisons in taxonomic composition of the toad's stomach contents and pitfall and sweeping net samples suggested ignorance or avoidance of Amphipoda by the toad. Our results suggest the possibility of considerable predation pressure of B. marinus upon the native arthropods, and ants in particular, on Ishigakijima Island.
\end{abstract}

The CANE TOAD, Bufo marinus, was originally distributed from the southernmost tip of the United States and western Mexico to central Brazil (Zug and Zug 1979, Lever 2001). In addition, it has been introduced to various Caribbean and Pacific islands and Australia as a biological agent to control sugarcane

${ }^{1}$ This study was conducted as a part of research activity in the Summer Course of the 21st Century Center of Excellence (COE) Program "The Comprehensive Analyses on Biodiversity in Coral Reef and Island Ecosystems in Asian and Pacific Regions" at the University of the Ryukyus under the auspices of the Japan Ministry of Education, Culture, Sports, Science, and Technology (Monbu-kagaku-sho). Manuscript accepted 24 August 2007.

${ }^{2}$ Graduate School of Engineering and Science, University of the Ryukyus, Nishihara, Okinawa 903-0213, Japan.

${ }^{3}$ Faculty of Science, Chulalongkorn University, $\mathrm{Pa}-$ tumwan, Bangkok 10330, Thailand.

${ }^{4}$ Faculty of Science, University of the Ryukyus, Nishihara, Okinawa 903-0213, Japan.

${ }^{5}$ Tropical Biosphere Research Center, University of the Ryukyus, Nishihara, Okinawa 903-0213, Japan.

${ }^{6}$ Corresponding author: (e-mail: ota@sci.u-ryukyu .ac.jp).

Pacific Science (2008), vol. 62, no. 3:423-430

(C) 2008 by University of Hawai'i Press

All rights reserved pests (Easteal 1981, Lever 2001). In Japan, this toad has been introduced to two groups of oceanic islands (the Daito Islands and the Ogasawara Islands) and an old continental island (Ishigakijima, Yaeyama Group) of the southern Ryukyus (Ota et al. 2004). Initially introduced as 10 or perhaps slightly more individuals to Ishigakijima in 1978, B. marinus now occurs abundantly throughout most of that island (Ota 1999).

Introduced species are of concern from a conservation perspective because exotic species, once established as breeding populations, can impact biodiversity through various interactions with indigenous species, such as predation, competition, and introgression (IUCN 2000). These interactions are potentially of great concern on long-isolated islands such as the Ryukyu Islands, because insular endemic species have long evolved in the absence of strong predators and powerful competitors (Case et al. 1992). However, this theoretical prediction still needs verification by actual field data, and in this regard, elucidation of the pattern and extent of influences of the introduced B. marinus on the native biota of Ishigakijima deserves serious study. As a first step in the study of cane toad impact, we investigated the dietary habits of $B$. mari$n u s$ on Ishigakijima by examining stomach contents of field-captured toads. 


\section{MATERIALS AND METHODS}

\section{Study Sites}

From 20 to 29 July 2006, we collected $B$. marinus by hand at night at three sites on Ishigakijima. These three sampling sites were selected to represent different habitat types: Site 1 , the shore of a very slowly moving shallow freshwater pond (ca. $1,200 \mathrm{~m}^{2}$ in area) in Banna Park (henceforth referred to as POND); Site 2 , a path $(500 \mathrm{~m}$ in total length, $5 \mathrm{~m}$ in width of the extent surveyed) in a well-recovering secondary forest of chiefly evergreen broadleaf trees in Banna Park (FOREST); Site 3, rice paddies (ca. 25,600 $\mathrm{m}^{2}$ ) in Nagura (RPF).

\section{Stomach Contents Analyses}

We anesthetized each toad captured by $8 \%$ ethanol in the laboratory until death. We measured the body weight (BW) to the nearest $0.1 \mathrm{~g}$ by electronic balance, and snout-tovent length (SVL) and mouth width (MW) to the nearest $0.1 \mathrm{~mm}$ by dial calipers. Specimens were then fixed in $10 \%$ formalin solution. After 2-3 days of fixation, the stomach was removed from each specimen, and its contents were extracted and stored in 10\% formalin solution. Each item from the stomach contents was identified to the lowest possible taxonomic level under a binocular microscope. Then, the minimum individual number was estimated and the total wet weight was measured (to the nearest 0.0001 $\mathrm{g}$ by electric balance $[\mathrm{A} \& \mathrm{D}$ Company ER182A]) for each taxon from each stomach. For items apparently maintaining their original body shapes, maximum length (L) and maximum width $(\mathrm{W})$ were also measured to the nearest $0.5 \mathrm{~mm}$. Then, volume of each animal $(\mathrm{V})$ was calculated using the formula for an ellipsoid volume as:

$$
\mathrm{V}=4 / 3 \quad(\mathrm{~L} / 2)(\mathrm{W} / 2)^{2}
$$

To estimate availabilities of potential prey taxa, we sampled insects and other small animals at each site by pitfall trapping and net sweeping. We conducted these samplings from sunset of 28 July to sunrise of 29 July
2006 to capture only nocturnal animals that should commonly encounter active B. marinus. As pitfalls, we set a total of 10,46, and 50 plastic cups $(90 \mathrm{~mm}$ diameter, $130 \mathrm{~mm}$ depth) in burrows prepared on the ground surface at POND, FOREST, and RPF, respectively. To prevent trapped animals from escaping, each cup was filled with sodium sorbate solution to approximately $2-3 \mathrm{~cm}$ from the bottom. At each site, sweeping was repeated three times using a net $(1 \mathrm{~mm}$ mesh, $37 \mathrm{~cm}$ opening diameter) near the ground surface, occasionally slightly touching upper portions of grasses and shrubs. Contents of cups and nets were fixed in $80 \%$ ethanol solution, and the potential prey were identified to the lowest possible taxonomic level. For each animal, maximum length and maximum width were measured to the nearest $0.5 \mathrm{~mm}$.

To examine a possible effect of the mouth size of the toad on its prey size preference, we also examined by regression analysis correlations of mean, maximum, and minimum values of prey width and prey length with MW in each toad. Data for toads that had no animal material in their stomachs were excluded from the analysis.

Resultant data were checked for normality and homoscedasticity in distribution. When these assumptions were met, they were analyzed parametrically. If not met, nonparametric statistics were used for the analyses. Potential size differences in the toads among the three sites were examined by comparing BW and SVL using one-way analysis of variance (ANOVA) or a Kruskal-Wallis test. An alpha level of 0.05 was used in all statistical tests.

\section{RESULTS}

At POND, FOREST, and RPF, we collected 18,14 , and 28 toads, respectively (i.e., 60 in total). Of these, one from FOREST was obviously a juvenile, measuring $20.3 \mathrm{~mm}$ in SVL. The others were subadults or adults with SVLs ranging from 65.1 to $151.8 \mathrm{~mm}$ (mean $\pm \mathrm{SD}=117.1 \pm 24.5 \mathrm{~mm}$ ), 77.2 to $162.5 \mathrm{~mm}(110.9 \pm 22.4 \mathrm{~mm})$, and 63.5 to $149.6 \mathrm{~mm}(106.3 \pm 18.4 \mathrm{~mm})$, and BWs 
Diet of Introduced Cane Toad in the Ryukyus - Kidera et al.

TABLE 1

Diet Composition (\%) of Bufo marinus at POND (793 Prey from 18 Toads), FOREST (927 Prey from 13 Toads), and RPF (406 Prey from 27 Toads)

\begin{tabular}{|c|c|c|c|c|c|c|c|c|c|}
\hline \multirow[b]{2}{*}{ Prey Taxon } & \multicolumn{3}{|c|}{ Frequency of Occurrence } & \multicolumn{3}{|c|}{ Numerical Proportion } & \multicolumn{3}{|c|}{ Volumetric Proportion } \\
\hline & POND & FOREST & $\mathrm{RPF}$ & POND & FOREST & RPF & POND & FOREST & RPF \\
\hline \multicolumn{10}{|l|}{ Insecta } \\
\hline Hymenoptera & 61.1 & 84.6 & 48.1 & 58.0 & 46.4 & 66.5 & 0.3 & 1.1 & 0.7 \\
\hline Coleoptera & 72.2 & 69.2 & 37.0 & 11.3 & 6.6 & 7.1 & 18.9 & 53.5 & 9.0 \\
\hline Coleoptera: larva & 0 & 15.4 & 0 & 0 & 0.6 & 0 & 0 & 0.1 & 0 \\
\hline Hemiptera & 66.7 & 69.2 & 14.8 & 5.3 & 21.8 & 1.7 & 3.5 & 3.8 & 1.0 \\
\hline Lepidoptera: larva & 44.4 & 30.8 & 3.7 & 13.4 & 6.3 & 0.7 & 44.9 & 23.4 & 4.3 \\
\hline Diptera & 5.6 & 0 & 7.4 & 0.1 & 0 & 0.5 & $0^{a}$ & 0 & $0^{a}$ \\
\hline Diptera: larva & 0 & 0 & 22.2 & 0 & 0 & 9.1 & 0 & 0 & 38.9 \\
\hline Blattodea & 27.8 & 23.1 & 7.4 & 1.5 & 0.4 & 0.5 & 0.4 & 8.9 & 2.7 \\
\hline Orthoptera & 27.8 & 30.8 & 18.5 & 1.4 & 0.5 & 2.0 & 1.6 & $0^{a}$ & 0.1 \\
\hline Dermaptera & 22.2 & 46.2 & 11.1 & 0.5 & 6.4 & 0.7 & 0.1 & 0.7 & 1.5 \\
\hline Thysanoptera & 5.6 & 0 & 0 & 0.1 & 0 & 0 & $<0.1$ & 0 & 0 \\
\hline Neuroptera & 5.6 & 0 & 0 & 0.1 & 0 & 0 & $0^{a}$ & 0 & 0 \\
\hline Odonata & 0 & 0 & 3.7 & 0 & 0 & 0.2 & 0 & 0 & $0^{a}$ \\
\hline Odonata: nymph & 0 & 0 & 3.7 & 0 & 0 & 0.2 & 0 & 0 & $0^{a}$ \\
\hline Isoptera & 0 & 23.1 & 0 & 0 & 3.1 & 0 & 0 & 0.1 & 0 \\
\hline \multicolumn{10}{|l|}{ Arachnida } \\
\hline Opiliones & 5.6 & 15.4 & 0 & 0.1 & 0.8 & 0 & $0^{a}$ & 0.4 & 0 \\
\hline Acari & 0 & 0 & 3.7 & 0 & 0 & 0.2 & 0 & 0 & $<0.1$ \\
\hline Thelyphonida & 0 & 7.7 & 0 & 0 & 0.1 & 0 & 0 & 2.2 & 0 \\
\hline Araneae & 66.7 & 30.8 & 25.9 & 5.0 & 1.9 & 2.2 & 1.4 & 4.6 & 1.6 \\
\hline \multicolumn{10}{|l|}{ Crustacea } \\
\hline Isopoda & 5.6 & 23.1 & 7.4 & 0.3 & 2.4 & 3.0 & 0.2 & 0.2 & 0.9 \\
\hline Amphipoda & 0 & 15.4 & 3.7 & 0 & 0.3 & 0.2 & 0 & 0.1 & 0.5 \\
\hline Decapoda & 11.1 & 0 & 3.7 & 1.0 & 0 & 0.2 & 25.4 & 0 & 21.2 \\
\hline Diplopoda & 16.7 & 15.4 & 22.2 & 0.6 & 0.2 & 1.7 & $0^{a}$ & $0^{a}$ & 1.5 \\
\hline Chilopoda & 5.6 & 15.4 & 0 & 0.1 & 0.5 & 0 & $<0.1$ & $<0.1$ & 0 \\
\hline Gastropoda & 22.2 & 30.8 & 29.6 & 1.0 & 1.3 & 3.0 & 3.1 & 0.9 & 16.1 \\
\hline Nematoda & 0 & 7.7 & 0 & 0 & 0.2 & 0 & 0 & $0^{a}$ & 0 \\
\hline Squamata & 0 & 7.7 & 0 & 0 & 0.1 & 0 & 0 & $0^{a}$ & 0 \\
\hline Plants & 94.4 & 84.6 & 63.0 & - & - & - & - & - & - \\
\hline Stones & 33.3 & 61.5 & 33.3 & - & - & - & - & - & - \\
\hline
\end{tabular}

Note: For groups belonging to the Insecta, those not identified as larva and nymph refer to adult individuals only.

${ }^{a}$ Items represented only by much-digested remains, and therefore their volumes were not calculated.

from 30 to $400 \mathrm{~g}(175.0 \pm 101.5 \mathrm{~g}), 45$ to $500 \mathrm{~g}(167.3 \pm 122.6 \mathrm{~g})$, and 25 to $380 \mathrm{~g}$ $(115.0 \pm 67.3 \mathrm{~g})$, respectively. No significant differences were recognized in either of these variables among the three samples (SVL: one-way ANOVA, $F=2.09$; $\mathrm{df}=2,56 ; P=$ 0.13 ; BW: Kruskal-Wallis test, $H=5.77$, $\mathrm{df}=2, P=0.06)$.

Two specimens had empty stomachs (the one juvenile from FOREST and one adult male from RPF $[S V L=111.8]$ ). The remain- ing 58 stomachs, each with one or more prey items, contained a total of 2,126 prey. We categorized these into 29 groups, along with plant materials and minerals (Table 1). Of the insect prey, hymenopterans (mostly ants), adult coleopterans, and hemipterans were the most frequent prey at all three sites (Hymenoptera: $61.1 \%, 84.6 \%$, and $48.1 \%$; adult Coleoptera: $72.2 \%, 69.2 \%$, and $37.3 \%$; and Hemiptera: $66.7 \%, 69.2 \%$, and $14.8 \%$ in POND, FOREST, and RPF samples, respec- 
tively). With regard to the numerical proportion, Hymenoptera dominated in all samples (58.0\% in POND, $46.4 \%$ in FOREST, and $66.5 \%$ in RPF samples). The most dominant groups, however, differed among habitats in volumetric proportion: larval Lepidoptera at POND (44.9\%), adult Coleoptera at FOREST (53.5\%), and larval Diptera at RPF (38.9\%). Of the noninsect prey, Araneae and Gastropoda were dominant in frequency of occurrence (25.9-66.7\% and 22.2-30.8\%, respectively), whereas Decapoda dominated in the volumetric proportion at POND $(25.4 \%)$ and RPF (21.2\%) (Table 1).

The numerical proportions of the seven groups that occupied more than $15 \%$ in either pitfall samples or sweeping net samples or stomach contents from at least one of the three sites are shown in Figure 1. This figure shows that at each site the cane toads took some prey taxa in proportions much different from that in our prey sampling. At POND and RPF, for example, Hymenoptera (mostly ants) were much greater in proportion in the diet $(58.0 \%$ at POND and $66.5 \%$ at RPF) than in pitfall samples $(11.0 \%$ at POND and $18.1 \%$ at RPF). In contrast, Hemiptera at POND and adult Diptera at RPF, although showing very high proportions in sweeping net samples $(60.7 \%$ and $57.5 \%$, respectively), were found in low proportions in the stomach contents at those sites $(5.3 \%$ and $0.5 \%$, respectively). Furthermore, very few Amphipoda, if any $(0-0.3 \%)$, and no Collembola were eaten at all sites, although both of these groups occupied substantial proportions in pitfall samples at two of the sites (Amphipoda: $74.7 \%$ at POND and $26.6 \%$ at FOREST; Collembola: $19.6 \%$ at FOREST and $19.4 \%$ at RPF).

The maximum and mean prey width and the maximum and mean prey length per stomach correlated significantly with the toad's mouth width $\left(r_{\max }=0.39\right.$ and $P_{\text {max }}<0.01$, and $r_{\text {mean }}=0.29$ and $P_{\text {mean }}<0.05$ for prey width [Figure 2]; $r_{\max }=0.38$ and $P_{\text {max }}<0.01$, and $r_{\text {mean }}=0.30$ and $P_{\text {mean }}<0.05$ for prey length). Likewise, both the minimum prey width and minimum prey length per stomach tended to be correlated with the latter variable, although the statistical supports were marginal $\left(r_{\min }=0.29\right.$ and $P_{\min }=0.05$ for prey width [Figure 2]; $r_{\min }=0.28$ and $P_{\min }=0.06$ for prey length).

\section{DISCUSSION}

The diet of Bufo marinus from Ishigakijima consisted of a wide variety of insects and other terrestrial invertebrates (Table 1). This result is consistent with several previous studies on the dietary habits of B. marinus from other regions (e.g., Zug et al. 1975, Zug and Zug 1979, Matsumoto et al. 1984, Strussman et al. 1984, Evans and Lampo 1996). Matsumoto et al. (1984) examined diets of a nonnative population of this toad in the Ogasawara Islands and found that the dominant prey taxon in mass varies among sites. In our study, the volumetrically dominant prey also varied among the three sites. This seems to reflect high dietary flexibility of B. marinus, and this flexibility may be responsible for the success of this toad in introduced and native areas, along with its high fecundity (Breder 1946) and possession of effective antipredator chemicals (Licht and Low 1968, Covacevich and Archer 1975, Phillips et al. 2003).

Toads of the genus Bufo have been regarded as indiscriminate predators because they consume a wide variety of arthropods including ants, beetles, and centipedes that are unpalatable to many other amphibians (e.g., Smith and Bragg 1949, Berry and Bullock 1962, Zug and Zug 1979). However, most previous studies did not investigate potential prey in the environment available to the toads and thus failed to verify this view appropriately. In consideration of this problem, we examined not only the stomach contents but also potential prey taxa of $B$. marinus in the environment. The results indicated that the toad eats ants in good number and high frequency despite their much smaller numerical proportion in our pitfall and sweeping net samples. In contrast, adult Diptera, Amphipoda, and Collembola were seldom found in the toad's stomach despite their high abundance in either pitfall samples, or sweeping net samples, or both.

Several previous authors have already re- 

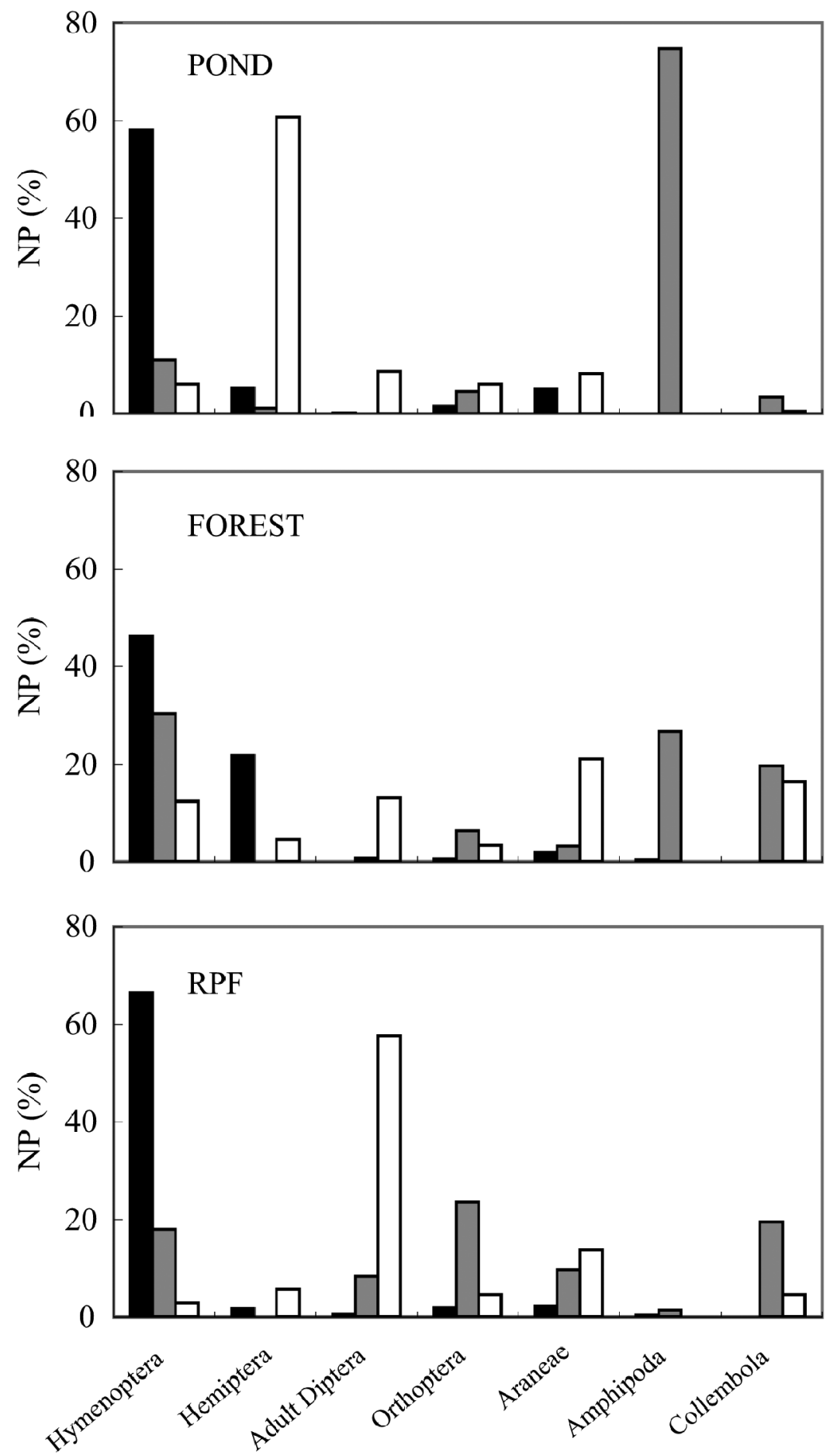

FIGURE 1. Numerical proportions (NPs) of the major prey groups in the stomach contents of B. marinus (black bars) and pitfall (gray bars) and sweeping net (open bars) samples collected at the three sites. 


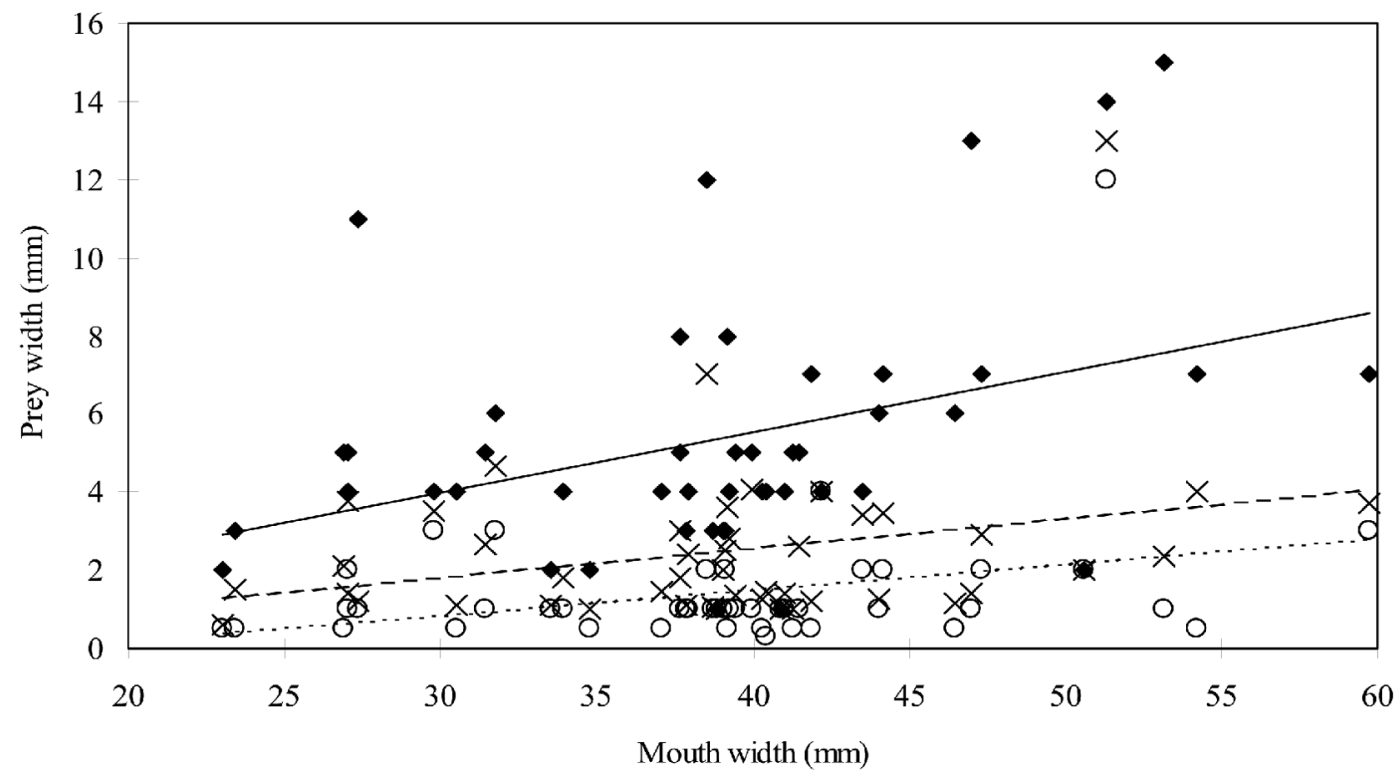

FIGURE 2. Correlations of mouth width of the toad B. marinus with maximum $(\diamond)$, mean $(\times)$, and minimum (o) values of prey width for each individual stomach $(n=49)$. Lines show least square regressions with equations of $y=0.16 x-0.65$ (solid line), $y=0.08 x-0.44$ (dashed line), and $y=0.08 x-1.08$ (dotted line).

ported numerical dominance of ants in the stomach contents samples of Bufo species including B. marinus (e.g., Zug and Zug 1979, Toft 1981, Strussman et al. 1984, Hirai and Matsui 2002, Isacch and Barg 2002). Our results further confirm this tendency. Based on the much smaller numerical proportions of ants in pitfall and sweeping net samples than in the toads' stomach, one may argue that the toad prefers ants over other potential prey. However, because pitfall trapping is not necessarily an appropriate method for quantitative evaluation of available prey in a given environment (Cornish et al. 1995), we defer conclusion on this issue to further studies employing other approaches.

It is probable that the observed rates of myrmecophagy of toads may result from efficient utilization of aggregating prey. Zug and Zug (1979) examined the cane toad diet from urban areas in Panama and found it to be composed largely of light-attracted insects, such as beetles. Matsumoto et al. (1984) noted that in the Ogasawara Islands some cane toad stomachs were filled with Dipteran larvae living in large numbers in fish carrion on the seashore. In our study, many individuals with similar digestive conditions of coprophagous insects and true bug species with aggregating habit (e.g., Tullberg et al. 2000, Kohno and Bui Thi 2005) were occasionally found from single toad stomachs. These observations further support the view that $B$. marinus eats a large number of prey individuals at a time once it detects their aggregation.

High numerical proportions in the environmental samples and much lower proportions or complete absence in the toads' stomach of adult Diptera, Amphipoda, and Collembola also need careful consideration. Adult Diptera may simply be too agile for the toad to catch, and Collembola, measuring $<3 \mathrm{~mm}$ in length, may be too small to attract toads' attention (Zug and Zug 1979, Matsumoto et al. 1984). Almost complete absence of Amphipoda in the stomach of $B$. marinus deserves special attention, because this group of arthropods was abundant in the pitfall samples at POND and FOREST. Moreover, Amphipoda are actually fre- 
quently preyed upon by several frogs that are sympatric with $B$. marinus on Ishigakijima (N.K., M.I., and H.O., unpubl. data). It is therefore likely that $B$. marinus ignores or avoids Amphipoda in feeding. This result seems to offer counterevidence to the conventional view that $B$. marinus is an indiscriminate feeder.

In some species of the genus Bufo, ontogenetic shifts of prey size have been documented (Flowers and Graves 1995, Hirai and Matsui 2002). Our analyses also indicated that B. marinus tends to prefer larger prey. Significant and marginally significant positive correlations of the toad's mouth width, respectively, with the maximum and minimum prey widths suggest that the toad more or less selects prey that are large enough to ensure recovery of the energy involved in ingestion.

The stomach contents of B. marinus revealed in our study included several native ants, such as Anochetus shobki, Camponotus monju, C. bishamon, and Pachycondyla luteipes (see Yamane et al. 1999), and other native insects, such as Serrognathus platymelus sakishimanus. This implies impact on the native arthropod fauna of this island from predation by the toad. Considering its frequent massive predation on ants, effect of predation pressure of $B$. marinus on those native ants, including one endemic to Ishigakijima ( $A$. shobki), needs special attention. Also, $B$. marinus on Ishigakijima may possibly impose competitive exclusion pressure on some native ant-eating species, such as Microbyla okinavensis (see Hirai and Matsui 2000: as $M$. ornata). Future studies are needed to examine stability in the dietary pattern of $B$. marinus on Ishigakijima outlined by this study on the basis of additional stomach contents samples collected in other seasons.

\section{ACKNOWLEDGMENTS}

We thank International Coral Reef Research and Monitoring Center, Japan Ministry of Environment, for logistic support, and the authority at the Banna Park Office, Department of Agriculture and Fisheries Economy, Ishigaki City Government, and S. Nakato for permission for fieldwork in land areas in their care. We also thank A. Nakamoto, S. Moteki, and S. Tanaka for helping with data analyses, M. Suwabe for helping with identification of ants, and two anonymous reviewers for improving an early version of the manuscript.

\section{Literature Cited}

Berry, P. Y., and J. A. Bullock. 1962. The food of the common Malayan toad, Bufo melanostictus Schneider. Copeia 1962:736741.

Breder, C. M. 1946. Amphibians and reptiles of the Rio Chucunaque drainage, Darien, Panama, with notes on their life histories and habits. Bull. Am. Mus. Nat. Hist. 86:375-435.

Case, T. J., D. T. Bolger, and A. D. Richman. 1992. Reptilian extinctions: The last ten thousand years. Pages 91-125 in P. L. Fiedler and S. K. Jain, eds. Conservation biology. Chapman and Hall, New York.

Cornish, C. A., R. S. Oldham, D. J. Bullock, and J. A. Bullock. 1995. Comparison of the diet of adult toads (Bufo bufo L.) with pitfall trap catches. Herpetol. J. 5:236-238.

Covacevich, J., and M. Archer. 1975. The distribution of the cane toad, Bufo marinus, in Australia and its effects on indigenous vertebrates. Mem. Queensld. Mus. 17:305310.

Easteal, S. 1981. The history of introductions of Bufo marinus (Amphibia:Anura): A natural experiment in evolution. Biol. J. Linn. Soc. 16:93-113.

Evans, M., and M. Lampo. 1996. Diet of Bufo marinus in Venezuela. J. Herpetol. 30:7376.

Flowers, M. A., and B. M. Graves. 1995. Prey selectivity and size-specific diet changes in Bufo cognatus and B. woodhousii during early postmetamorphic ontogeny. J. Herpetol. 29:608-612.

Hirai, T., and M. Matsui. 2000. Ant specialization in diet of the narrow-mouthed toad, Microbyla ornata, from Amamioshima Island of the Ryukyu Archipelago. Curr. Herpetol. 19:27-34. 
icus formosus from montane region of Kyoto, Japan. J. Herpetol. 36:719-723.

Isacch, J. P., and M. Barg. 2002. Are bufonid toads specialized ant-feeders? A case test from the Argentinian flooding pampa. J. Nat. Hist. 36:2005-2012.

IUCN. 2000. Guidelines for the prevention of biodiversity loss due to biological invasion. IUCN, The World Conservation Union, Gland, Switzerland.

Kohno, K., and N. Bui Thi. 2005. Comparison of the life history strategies of three Dysdercus true bugs (Heteroptera: Pyrrhocoridae), with special reference to their seasonal host plant use. Entomol. Sci. 8:313-322.

Lever, C. 2001. The cane toad: The history and ecology of a successful colonist. Westbury Academic and Scientific Publishing, Otley, West Yorkshire, United Kingdom.

Licht, E. L., and B. Low. 1968. Cardiac response of snakes after ingestion of toad parotoid venom. Copeia 1968:547-551.

Matsumoto, Y., T. Matsumoto, and K. Miyashita. 1984. Feeding habits of the marine toad, Bufo marinus, in the Bonin Islands, Japan. Jpn. J. Ecol. 34:289-297.

Ota, H. 1999. Introduced amphibians and reptiles of the Ryukyu Archipelago, Japan. Pages 439-452 in G. H. Rodda, Y. Sawai, D. Chiszar, and H. Tanaka, eds. Problem snake management: The habu and the brown tree snake. Cornell University Press, New York.

Ota, H., M. Toda, G. Masunaga, A. Kikukawa, and M. Toda. 2004. Feral popula- tions of amphibians and reptiles in the Ryukyu Archipelago, Japan. Global Environ. Res. 8:133-143.

Phillips, B. L., P. B. Gregory, and R. Shine. 2003. Assessing the potential impact of cane toads on Australian snakes. Conserv. Biol. 17:1738-1747.

Smith, C. C., and A. N. Bragg. 1949. Observations on the ecology and natural history of toads in Oklahoma. Ecology 30:333349.

Strussman, C. M., B. Ribeiro do Vale, M. H. Meneghini, and W. E. Magnusson. 1984. Diet and foraging mode of Bufo marinus and Leptodactylus ocellatus. J. Herpetol. 18:138-146.

Toft, C. A. 1981. Feeding ecology of Panamanian litter anurans: Patterns in diet and foraging mode. J. Herpetol. 15:139-144.

Tullberg, B. S., G. G. Stille, and C. Solbreck. 2000. Effects of food plant and group size on predator defence: Differences between two co-occurring aposematic Lygaeinae bugs. Ecol. Entomol. 25:220-225.

Yamane, S., S. Ikudome, and M. Terayama. 1999. Identification guide to the aculeata of the Nansei Islands, Japan. Hokkaido University Press, Sapporo.

Zug, G. R., E. Lindgren, and J. R. Pippet. 1975. Distribution and ecology of the marine toad, Bufo marinus, in Papua New Guinea. Pac. Sci. 29:31-50

Zug, G. R., and P. B. Zug. 1979. The marine toad, Bufo marinus: A natural history resume of native populations. Smithson. Contrib. Zool. 284:1-58. 